\title{
In vitro and in situ Erosion Models for Evaluating Tooth Substance Loss
}

\author{
N.X. West ${ }^{a} \quad$ M. Davies ${ }^{\text {a }} \quad$ B.T. Amaechi ${ }^{b}$ \\ ${ }^{a}$ Clinical Trials Unit, School of Oral and Dental Sciences, University of Bristol, Bristol, UK; \\ ${ }^{b}$ Cariology Group, Department of Comprehensive Dentistry, University of Texas Health \\ Science Center at San Antonio, San Antonio, Tex., USA
}

\section{Key Words}

Clinical studies $\cdot$ Erosion $\cdot$ Erosive tooth wear .

In situ model $\cdot$ In vitro model

\begin{abstract}
Because of the difficulties in measuring erosion in vivo, a number of in vitro and in situ models have been developed and validated. These models are flexible and informative, allowing single as well as multiple variables to be examined under specific conditions using accurate measurement techniques over defined timelines, thus yielding useful data without harmful effects on individuals. This information, together with clinical findings, is essential for clinicians advising susceptible patients appropriately regarding the management of their condition. Little guidance is available, however, on the standardisation of in vitro and in situ protocols for erosive tooth wear studies, so it is difficult to make meaningful comparisons between investigations as experimental variables differ widely from study to study. The aim of this review was to collate the available data on models designed to assess erosive challenges which are severe enough to cause tissue loss as opposed to just softening of the surface structure. The different types of models, with their merits and pitfalls, are documented. Test substrates, disinfecting regimens and ethical considerations are discussed. The aims
\end{abstract}

of this paper are to give guidance to the researcher on evidence-based in vitro and in situ erosive tooth wear methodology and to suggest best practice given current knowledge.

Copyright $\odot 2011$ S. Karger AG, Basel

Erosive tooth wear is common amongst many populations today and the prevalence is increasing [Al Dlaigan et al., 2001]. Of the two main aetiological determinants for erosion, extrinsic and intrinsic acids [Bartlett, 2009], the former is more prevalent. The continual increase in the consumption of soft drinks worldwide [British Soft Drinks Association, 2010; Research and Markets, 2010], combined with copious evidence [Tahmassebi et al., 2006] that in a susceptible individual frequent acidic challenges can result in tooth substance loss, reinforces the need to better understand erosive tooth wear.

Studies to test the erosivity of individual products or to test possible methods for prevention would ideally be conducted in vivo, using intra-oral measurement of tooth tissue loss. The randomised clinical trial would be the gold standard for this kind of study. Unfortunately, in vivo studies are renowned for their inability to achieve very precise tooth wear measurements. The main impediment is probably the low accuracy of available methods

\section{KARGER}

Fax +4161306 1234

E-Mail karger@karger.ch

www.karger.com
(C) 2011 S. Karger AG, Basel

0008-6568/11/0457-0043\$38.00/0

Accessible online at:

www.karger.com/cre
Prof. N.X. West

Clinical Trials Unit, School of Oral and Dental Sciences

Bristol Dental School, Lower Maudlin Street

Bristol BS1 2LY (UK)

Tel. +44 117342 4505, E-Mail N.X.West@Bristol.ac.uk 
for measurement of tooth tissue loss in vivo [Huysmans et al., 2011]. Other factors include: uncertainty about the pattern of progression, which implies a need for studies of long duration; lack of control over exposure to wear, which makes it difficult to assess the effect of erosion alone, and the need to minimise contact of erosive agents with the dentitions of trial subjects.

In situ and in vitro models have been developed in attempts to overcome the challenges that hinder in vivo studies whilst still providing meaningful data that reflect what actually happens in the oral cavity. The main advantages of such models are that tight standardised controls can be implemented, one variable at a time can be examined, new variables can be introduced stepwise, and accurate measurement technologies over defined time periods can be used to determine loss of tooth tissue. In situ models offer the advantage that they allow control of the erosive challenge but also expose the specimens to the oral environment.

In the study by Young and Tenuta [2011], models concerned with initial erosion (enamel softening) are reviewed. The present paper discusses models involving tissue loss resulting from frequent or prolonged erosive challenges. The models discussed enable the erosive potential of dietary and gastric acids to be determined under standardised conditions over variable time periods and compared with other agents in an ethically sound way. They also allow other factors that could contribute to erosion to be assessed both simultaneously and additively. Finally, they have been an important tool in testing the effectiveness of preventive methods, such as the chemical modification of drinks.

\section{In vitro Models}

In vitro models are extremely useful because they can be executed over a short period of time, require fewer staff than in situ studies, avoid participant compliance issues and are relatively inexpensive. However, they cannot replicate the oral environment with all of the biological variations known to influence erosion.

Variables such as the erosive solution, the stirring method and rate, and the temperature of the experiment should be carefully described to enable comparison between studies. The stirring rate influences erosion by altering the thickness of the diffusion layer and hence the rate of dissolution [Barbour et al., 2005a]. Erosive solutions can be unstirred or stirred: magnetically, with an overhead stirrer or with a rotary mixer [Hughes et al., 1999a; Barbour et al., 2005a; Hooper et al., 2007a]. Temperature should be controlled, e.g. using refrigeration or water baths [Barbour et al., 2006] as, in general, erosion increases with increasing temperature [Amaechi et al., 1999b; West et al., 2000; Barbour et al., 2006]. An anomaly has been observed by Hooper [unpubl. data]. Citric acid heated to over $70^{\circ} \mathrm{C}$ and then cooled prior to exposure to the substrate causes less erosion than control citric acid, possibly because the acid is degraded.

A method in which both temperature and stirring, as well as $\mathrm{pH}$, are closely controlled is the $\mathrm{pH}$-stat, and this has proven useful in studying possible erosion inhibitors [Barbour et al., 2005b]. Using a sequence of control, test and post-test exposures, information has been obtained, not only about the effectiveness of inhibition but also about its persistence of action.

Matrices for acid characteristics can be designed and plotted to define the erosion potential for different variables such as time, concentration, titratable acidity and temperature [Amaechi et al., 1999b; Hughes et al., 2000].

One in vitro study indicated that there was no significant difference in depth of erosion between a regimen of four separate exposures per day to an erosive agent for 15 days, and a 'one-off' long soak of the same total exposure time [Hughes, 1999b].

In vitro models investigating remineralisation should use $\mathrm{pH}$ cycling, which can be done manually or under computer control. Various types of artificial mouth models are also available for use in in vitro studies, enabling standardised exposure of an agent to substrate in a controlled fashion, which attempts to replicate the oral environment over time, including salivary flow [Attin et al., 2003; Wiegand et al., 2009; Lee et al., 2010].

Tissue loss can be measured by several techniques [Schlueter et al., 2011], of which the most suitable is profilometry (either contact or non-contact instruments). Measuring tissue loss in dentine requires special precautions [Schlueter et al., 2011].

In vitro erosion rarely, if ever, agrees quantitatively with in situ erosion, since the natural protective effects from the oral cavity are lacking. In vitro erosion of human enamel by orange juice resulted in surface loss 10 times higher than that found in situ (20-30 vs. $2-3 \mu \mathrm{m})$ [West et al., 1998]. In vivo, many factors modify erosion: the teeth are protected by the salivary pellicle [Amaechi et al., 1999c; Hara et al., 2006], and saliva itself affords buffering potential [Meurman et al., 1987; Meurman and ten Cate, 1996], dilution of erosive agents [Mandel, 1987; Meurman and ten Cate, 1996] and remineralising effects [Mannerberg, 1963; Gedalia et al., 1991; Amaechi and 
Fig. 1. Examples of intra-oral appliances for in situ studies. a Palatal intra-oral appliance retaining 4 specimens. Wires ensure specimen fixation and protect the specimen from tongue friction. $\mathbf{b}$ Mandibular appliance.
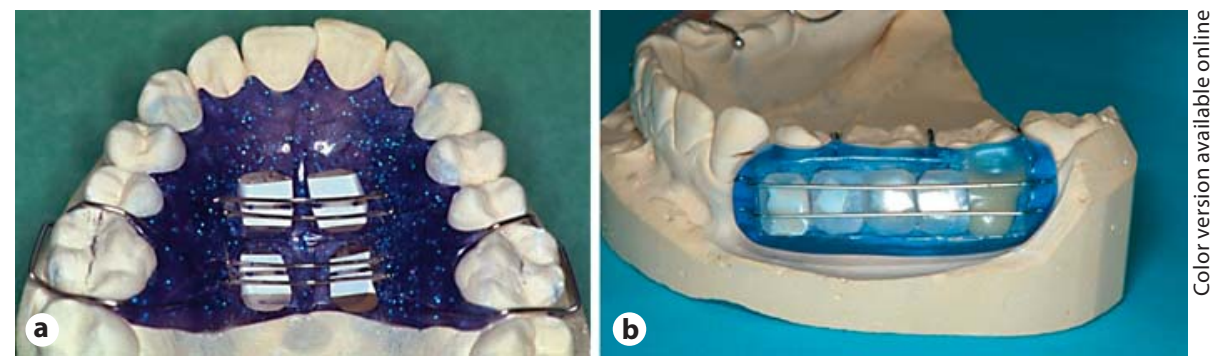

Higham, 2001a] to counteract the acid challenge. Ideally, in vitro models would incorporate exposure to natural human saliva, but this presents difficulties. Natural saliva is time consuming to collect and decomposes quickly [Schipper et al., 2007], so it has to be used in compliance with cross-infection procedures. Furthermore, human saliva is subject to regulations governing use of human tissues in the UK. Most existing in vitro models instead incorporate artificial saliva, of which there are numerous published recipes [Leung and Darvell, 1997]. Although most artificial saliva formulations lack salivary proteins and their important functions with regard to erosion, they simulate the ionic composition of human saliva and thus add the potential for remineralisation to the model [Mannerberg, 1963; Devlin et al., 2006; Magalhães et al., 2010].

In summary, although they are simple systems without the complex interactions found in vivo or in situ, in vitro models do have a number of advantages for erosion research. Primarily, they provide data that can be used to define the trajectory for the researcher to follow and refine prior to conducting studies in the clinical environment. They allow a large number of variables to be examined and trends to be identified, which is invaluable for optimisation of clinical study conduct from both ethical and time efficiency perspectives. Sizeable numbers of specimens can be tested, and variation between specimens analysed without the confounding variables of the subject and the oral environment. Data from these preliminary studies facilitate power calculations to determine the required number of participants for a subsequent in situ study. Positive, negative and benchmark controls can be validated and the outcome of specific variables narrowed down. While in vitro investigations are unlikely to fully agree quantitatively with the findings of in situ or in vivo studies, in situ findings usually follow the trends observed in vitro [West et al., 1999; Hannig et al., 2004; Young et al., 2006; Hooper et al., 2007a].

In vitro and in situ Erosion Models
Once a clear direction for further investigation has been established through in vitro studies, it can be followed up by in situ studies, which are closer to natural conditions and thus produce more clinically relevant results.

\section{In situ Models}

In these models, specimens of dental tissue are carried in the mouth and are exposed to erosive challenges or other treatment at pre-determined times, either intraorally or ex vivo. Tissue loss is measured ex vivo, permitting the use of accurate analytical methods. In situ models thus provide a method of accurately measuring tissue loss over time in a more or less completely natural environment of saliva flow, pellicle development and routine oral care. They allow studying the potential of various agents to cause erosion or to provide protection against erosion. Modelling needs to take into account (a) the chemical nature of the test agent; (b) the behavioural factors associated with drinking; (c) the influence of individual biological factors such as saliva, the remineralisation potential and the inherent nature of the tooth, and (d) physical processes within the oral environment, e.g. mastication, tooth brushing, tooth-tooth contact and movement of the soft tissues over the teeth. Once a reproducible in situ methodology has been developed, the model can be used to evaluate the erosion potential of a test agent by comparison with validated negative and positive controls, such as water and orange juice [West et al., 1998, 1999]. Subsequent studies can then determine, for example, the effect of frequency and duration of exposure on surface loss.

Broadly, in situ models use two approaches: (1) removable appliances with intermittent or continuous presence in the mouth, or (2) fixed appliances with continuous presence in the mouth. 
Fig. 2. Clinical photograph of an enamel specimen housed in a fixed erosion-abrasion model for evaluation of an agent. a Remineralisation potential (without mouthguard). b Erosive potential (with mouthguard).
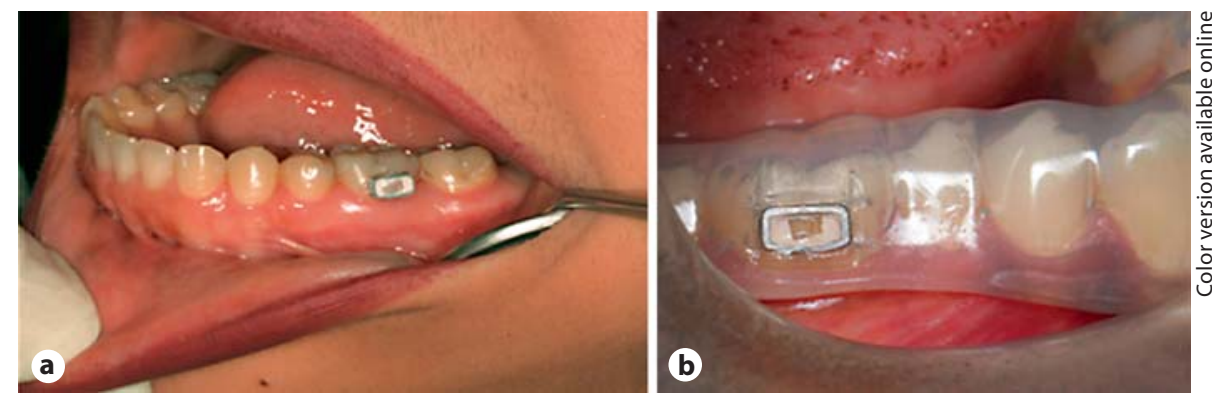

\section{Removable-Appliance Models}

With intermittent application, the appliances (fig. 1) are worn by subjects only under supervision, e.g. during office hours, but are removed from the mouth during outof-office time, including night-times [West et al., 2003, 2004]. With such a regimen, the compliance of participants can be monitored by the trial co-ordinators, and strict standardised conditions of treatment can be imposed, and variation in subject behaviour, always a problem with studies in humans, is minimised. Very strict regimens can be documented in the protocol, and clear conclusions from such studies can be drawn. In contrast, when removable appliances are continuously present in the mouth, volunteers may be asked to take the appliance out periodically, for example during eating, drinking or smoking, but otherwise to wear them at all times. In these studies, compliance can be an issue, but a more realistic model of erosion is obtained because overnight exposure to oral conditions incorporates the possible beneficial effects of remineralisation into the model [Abdullah et al., 2006; Laheij et al., 2010]. If the appliances are worn at all times, even during eating, drinking and smoking, the model is complicated by variables which increase the standard deviations in the analyses, e.g. erosion by dietary substances other than the test product. The power of the study then has to be maintained using large numbers of participants, which increases the costs of the research.

\section{Fixed-Appliance Models}

To overcome problems of compliance in studies where specimens are retained in the oral cavity at all times, they may sometimes be fixed to participants' teeth (fig. 2a) for short periods of time [Amaechi et al., 2000; Amaechi and Higham, 2001b; Amaechi et al., 2010]. The fixed appliance with continuous presence in the mouth enables the specimens to be subjected to all the daily processes occurring within the oral cavity. Where such models are used to evaluate the erosive potential of an agent, upper and lower soft mouthguards can be used to protect the participant's teeth from contact with the test agent during intake, a window in the guard accommodating and exposing the specimen to the agent (fig. $2 \mathrm{~b}$ ).

\section{Study Design}

Crossover design studies are usually used. For a study with, for example, 3 drinks, about 15-18 subjects are needed to give an $80 \%$ chance of identifying an effect of an erosive agent on 4 specimens over a 15-day period. These numbers will vary according to measurement accuracy and the magnitude of the difference considered relevant. Studies are usually single blind (i.e. with respect to the investigator conducting the analyses), randomised and placebo controlled. Analytical methods should accurately measure very small amounts of tissue loss: this shortens study duration and thus reduces the risk to the participant; clinically it is important to identify and treat lesions as early as possible. Utilising the same protocol for different trials improves reproducibility and the ability to estimate with some certainty the erosive potential of soft acidic beverages in situ.

Water is often included as a control, and this should produce negligible tissue change to validate the model. Any minimal variation around baseline can be explained in terms of surface roughness of the original specimen.

Specimens, especially of dentine, should not be allowed to dehydrate, and therefore when specimens are not in the mouth, they should be stored in a moist environment, e.g. a sealed pot containing a moist cotton wool roll. Plaque should be prevented from accumulating during a study, but specimens should not be brushed as this would accelerate tissue loss. An antimicrobial mouth rinse can be used to prevent plaque build-up, the gold standard being $0.2 \%$ chlorhexidine for $60 \mathrm{~s}$ at the end of each day and beginning of the next day [West et al., 1998]. There is some evidence that staining caused by chlorhexidine will inhibit erosion [Seong et al., unpubl. data], but 
with in situ models where participants refrain from eating and drinking while wearing their appliance, no dietary chromogens should be available for stain production. Recent in vitro data suggest that chlorhexidine rinses or gel may inhibit the erosion of dentine [Magalhães et al., 2009; Kato et al., 2010]. If appliances are retained in the mouth for eating and drinking, then other measures, such as brushing the specimens, need to be employed to prevent plaque accumulation, but such studies would then, of course, be concerned with erosive tooth wear rather than with erosion.

\section{Position of Specimens in the Mouth}

Several different designs of appliances carrying various numbers of tooth specimens in the mouth have been utilised [West et al., 1998; Amaechi et al., 2000; West et al., 2004; Zero et al., 2006; Amaechi et al., 2010]. A number of specimens can be retained palatally, either centrally in the midline or to the right or left, anteriorly or posteriorly, or in the lower arch buccally or lingually (fig. 1).

In palatal models, the specimens are well placed for capturing erosion data, although ideally they would be attached to the facial, palatal and occlusal surfaces of teeth where erosion is frequently located. Unfortunately, this is not possible because the location of specimens in such areas would interfere with the occlusion. In the palatal region, anteriorly placed specimens show more erosion than posteriorly placed specimens after in vivo challenge, but the differences were not significant [Hooper et al., 2007b]. Specimens can be protected from the abrasive influence of the tongue or buccal mucosa by, for example, retaining wires [West et al., 1998] or by recession of the specimen by about $0.5 \mathrm{~mm}$ below the contacting surface [Hara et al., 2009; Amaechi, 2010]. However, if treatment is in vivo, volunteers can guard the specimens with the tongue and prevent the erosive challenge, so it is sensible to teach volunteers how to drink or swish in such studies. In addition, care should be taken to ensure that the retaining apparatus does not stop the erosive agent reaching the required area of the specimen.

Lower buccal appliances with tooth specimens have been used, but these are protected by the buccal soft tissues and are more suited to erosion/abrasion models.

\section{Ex vivo versus in vivo Erosive Challenge}

Specimens can be treated intra-orally or ex vivo, or by a combination of both [Honório et al., 2008; Ganss et al., 2010]. The average volume of soft drink imbibed per day in the UK in a young adult is 1 litre [British Soft Drinks Association, 2010] and test volumes up to this have been used in in situ studies. From an ethical perspective, if volunteers are asked to imbibe an erosive agent, care must be exercised to ensure that their participation in the study does not significantly increase the risk to their teeth.

The advantage of challenging the tooth specimens ex vivo is that there is no chance of subjecting a susceptible individual to an erosive challenge with possible detrimental effects. The ex vivo challenge is also standardised. Since all specimens are subjected to exactly the same acidic conditions, tissue loss is less variable than after in vivo exposure, which is influenced by differences in the oral environment of the study participants. Honório et al. [2008] designed a flotation device which enables only the specimens on one side of a palatal appliance to be exposed to an erosive challenge, so that treated and control specimens can be held in the same appliance. An ex vivo erosive challenge will not be fully comparable with an in vivo challenge as the interactions between the erosive agent and saliva which occur during normal drinking, e.g. buffering by saliva, are missing.

When the challenge is in vivo, it is necessary either to protect the volunteer's teeth with a mouthguard as in figure $2 \mathrm{~b}$ or to withdraw participants from the study if the specimens they carry experience more than a predetermined level of erosive tissue loss (see below).

\section{Standardised Regimens}

The conditions used in in situ trials vary immensely, with each research group having their own regimens. For example, erosive challenge varies from in vivo exposure to 1 litre of an acidic soft drink per day for 15 days [West et al., 1998, 1999] to ex vivo immersion in $150 \mathrm{ml}$ of an acidic soft drink for $5 \mathrm{~min}$ three times per day over 14 days [Honório et al., 2008; Rios et al., 2009].

Protocols need to be adhered to when conducting clinical studies and should be clearly documented in published reports. Human variation being such as it is within a group of subjects asked to drink a fixed volume over a set period of time: there can be considerable variation in contact of the specimens with the erosive liquid. As indicated above, for an in vivo challenge participants need to be taught how to drink consistently. For example, they should be instructed not to cover palatal specimens with the tongue and to consume the correct volume in the set time; they may be instructed to rinse or to sip aliquots at short intervals.

If subjects are asked not to eat or drink, apart from water, when the appliance is in situ, this must be monitored and procedures put in place for storage of the specimens, for example over a lunch period of $1 \mathrm{~h}$. 
In order to reduce exacerbation of oral tissue loss by soft tissues, subjects should be instructed not to lick the specimens wherever they are placed in the mouth, as this has been demonstrated to increase the amount of tissue loss [Gregg et al., 2004; Vieira et al., 2006].

\section{Subject and Specimen Variation}

Of the experimental variables in studies in situ, the subject and the tooth specimen are the greatest source of variability. Some people can imbibe copious amounts of acidic beverages with no detrimental effects, whilst others are extremely vulnerable to acid attacks [Hughes et al., 1999b; Hooper et al., 2007a]. The number of times a specimen is measured has little impact on results [West et al., 2010, unpubl. data]. This would suggest that enough subjects and specimens need to be included in in situ studies to allow for these variations and that each specimen only needs to be measured once. The between-subject variations in tissue loss could be due to variations in saliva, in the presence and properties of the pellicle, in the properties of different specimens or in movements of the oral soft tissues. With regard to the pellicle, optimum protection appears to be achieved after pellicle formation times of $2 \mathrm{~h}$ or possibly less [Amaechi et al., 1999c; Wetton et al., 2006]. Thus, the design of in situ models should allow for pellicle formation prior to erosive challenge unless stated in the protocol.

\section{Ethical Considerations}

When an erosive agent is investigated in situ, erosion safety limits should be written into the protocol to ensure that the participants' oral health is maintained. For example, a limit of $20 \mu \mathrm{m}$ tooth substance loss from a specimen could be specified in the protocol [Hughes et al., 1999b; Hooper et al., 2007a], and volunteers could be withdrawn if this limit is reached. In the last 20 studies from the Clinical Trials Unit in Bristol, UK, over a 10year period, only 2 volunteers have been withdrawn for this reason [Hughes et al., 1999b; Hooper et al., 2007a].

Care also needs to be taken to ensure that the specimens are not lost, causing both ethical and conduct issues according to the Good Clinical Practice Guidelines [ICH Harmonised Tripartite Guideline for GCP, 1996]. The appliances holding specimens need to be robust and durable. To date, no loss of specimens has been documented in the literature.

Swallowing acidic soft drinks over 2 weeks or more in a study has been found to lead to adverse events, for example gastric irritation, so rinsing and spitting are preferred over a long study lasting months or longer [Claytor et al., 1941].
It is necessary to document in full the inclusion and exclusion criteria, which govern the suitability of volunteers for in situ studies. There should be clear guidance in the protocol that if individuals show signs of erosion they should not be recruited for studies in which an erosive agent is to be tested in vivo. Participants with a history of gastric regurgitation from conditions such as diabetes, anorexia, rumination and any current medication causing gastric reflux or xerostomia should be excluded.

\section{Test Substrate}

Most research on erosion has been concerned with enamel, although more recently there has been a growing interest in dentine, in part because of the evidence pointing to dentine hypersensitivity as a tooth wear phenomenon [Addy, 2005]. All the models described can accommodate either enamel or dentine or both substrates together in one study.

Human dental tissues are used with in situ models but, because of improvements in oral health care, it has become increasingly difficult to obtain human teeth for research. Moreover, the use of human teeth for research is increasingly subject to regulation. For these reasons, bovine dental tissues are frequently used instead [Zero et al., 2006; Rios et al., 2008; Hannig et al., 2010]. However, there are concerns as to whether data obtained from bovine and human teeth are always fully comparable. It is known that there are structural differences between bovine and human enamel [Featherstone and Mellberg, 1981]; bovine crystallites are thicker than their human counterparts [Arends and Jongebloed, 1978], and bovine enamel has a higher radiographic density [Tanaka et al., 2008]. Similarly, it has recently been shown that there are clear differences in dentinal tubule structure and morphology between bovine and human teeth [Lopes et al., 2009]. In vitro studies have provided some evidence that structural differences may result in differences in the behaviour of bovine and human teeth in a clinical setting. It has been demonstrated that the speed of erosion [Amaechi et al., 1999b] and the rate of demineralisation [Amaechi et al., 1999b; Kielbassa et al., 2006] are higher in bovine than in human enamel. The preventive effect of $\mathrm{TiF}_{4}$ against erosion [Hove et al., 2007] was much greater in bovine enamel. Following acid challenge and abrasion, human enamel had a significantly greater change in surface microhardness and showed less evidence of wear than bovine enamel [Rios et al., 2006]. Wegehaupt et al. [2008] showed that there was no significant difference between human third molars and cattle lower incisors following a combined erosive/abrasive challenge, suggesting that for this type of 
study bovine dentine might be used. However, this study also showed that, following an erosion-only challenge, there was significantly higher dentine loss in primary and permanent human teeth than in lower incisors of calves and cattle. Taken together, these findings suggest that wherever possible it is better to use human teeth for dental erosion studies. Indeed, it is doubtful if ethical approval would be given for bovine specimens to be placed in the mouth in in situ studies in the UK.

Usually, specimens are embedded in materials such as epoxy resin or composite in order to ensure retention in the appliance. In a review of the literature, no loss of specimens has been documented in the adverse events. Specimens can be used without being embedded, but they need to be able to be retained in the appliance, and a flattened surface may be necessary for measurement. For in vitro investigations, specimens can be masked with tape, nail varnish or bonding agents to reveal the test area. For in situ work, the masking must be biologically compatible and harmless in the oral environment.

Because of the reduction in dental extractions, there remains a chronic shortage of human tooth material and it is essential, therefore, to maximise the use of this valuable resource. Currently, in order to minimise variation between specimens, most studies using human teeth opt to use third molars [Hooper et al., 2007a]. Unerupted wisdom teeth are often preferred because of the lack of oral exposure, age of the patient (usually 20-30 years) and a lack of secondary and tertiary age-related changes to the tooth structure. It has been demonstrated in vitro that the lingual/palatal surfaces are more susceptible than labial/buccal surfaces to erosion [Tucker et al., 1998]. However, a recent study, including 199 specimens obtained from mesial, distal, buccal and lingual/palatal surfaces of 34 maxillary and 16 mandibular teeth cut at a depth of $200 \mu \mathrm{m}$ and subjected to an acid challenge, demonstrated that there was no significant difference in erosion depth between tooth surface or dental arch with regard to wisdom teeth [Hooper, unpubl. data]. This study therefore demonstrated that enamel specimens from any surface of third molars are suitable for use in erosion studies.

Natural tooth surfaces have been used in studies, but it is much harder to measure these irregular surfaces by conventional methods such as profilometry. Hence polished surfaces are usually utilised with fixed accurate reference points. Flat enamel surfaces have the surface layer removed and the erosion observed is the worst-case scenario, similar to the eroded clinical situation [Attin, 2006].

In vitro and in situ Erosion Models
When using tooth tissue specimens from different individuals, care should be taken to ensure that only 1 specimen from 1 particular donor is placed in the mouth of 1 volunteer to reduce bias.

\section{Tissue Disinfection}

The possibility of transmission of infectious micro-organisms through human or bovine teeth, especially with regard to human prion diseases, raises ethical problems for the conduct of studies. Hence the sterilisation of tooth specimens is usually a mandatory requirement for in situ models; 4,080 Gy of $\gamma$-irradiation given at a dose rate of $70-80 \mathrm{~Gy} / \mathrm{h}$ over $48 \mathrm{~h}$ has been found to be optimal for sterilisation of enamel specimens without effect on the structural integrity of either sound or demineralised tooth surface [Amaechi et al., 1999a]. However, the current literature is divided as to whether prions are inactivated by $\gamma$-irradiation. The WHO [1999] Infection Control Guidelines for Transmissible Spongiform Encephalopathies do not recommend this technique for prion sterilisation. By contrast, Miekka et al. [2003] demonstrated that $50 \mathrm{kGy}$ $\gamma$-irradiation inactivated almost all prion proteins, although there was some residual infectivity, suggesting that this technique may not be adequate for in situ studies. Ethylene oxide sterilisation administered as in the sterilisation of medical instruments may also be used [Hara et al., 2006; Vieira et al., 2007], but there is some evidence to suggest that it is ineffective in sterilising dentine [DeWald, 1997]. In some studies, disinfection is achieved by soaking crowns and roots from which the pulp and other debris have been removed in sodium hypochlorite for a number of hours [West et al., 1998; Hooper et al., 2007a]. Sodium hypochlorite is listed in the WHO Guidelines as an agent that can deactivate prions, and it is recommended that it is used together with standard sterilisation procedures for maximum effect. In some countries, an aqueous thymol solution is used to disinfect the teeth prior to use [Ganss et al., 2007; Hara et al., 2009], but it is not known whether it is fully effective against prions. Some studies have used $2 \%$ formaldehyde for 30 days at $\mathrm{pH} 7$ to disinfect teeth prior to use in situ [Rios et al., 2006], but there is concern regarding the toxicity of formaldehyde in vivo, and aldehydes are known to stabilise prions.

\section{Regulation of Use of Human Tissues}

In many countries, the use of human tissues in research is now subject to strict legislation. This affects the availability and use of human teeth and also the use of human saliva in erosion studies. The following comments arise from our experience in the UK and USA.

Caries Res 2011;45(suppl 1):43-52 
Teeth have become more difficult to acquire since the implementation of the Human Tissue Act 2004 (HTA) in September 2006 in the UK. Tissues (including saliva as well as teeth) can only be obtained and used for research by holders of HTA licences. It is now possible for HTA-licensed institutions to establish tissue banks to which tissues for which informed consent has been given may be donated, so that teeth do not have to be specially collected for each project [Human Tissue Authority, 2009]. Moreover, generic approval for research can be granted, so that tissues may be released for research from tissue banks without the need for project-specific ethics committee approval. However, the tight regulation of tissue banks increases the administrative load of research groups. Even with the advantages conferred by HTA-licensed tissue banks, tooth material is still not plentiful.

The situation is slightly different in the USA. Collection of biological specimens for research purposes by non-invasive means is under the supervision of the local Institutional Review Board. With their approval, teeth can be collected for research purposes if routine patient care indicates a need for extraction. Similarly, deciduous teeth can also be collected at the time of exfoliation, while uncannulated saliva can be collected either in an unstimulated fashion or stimulated by chewing gum base or wax, or by applying a dilute citric solution to the tongue.
However, human teeth for research are also scarce in the USA because of less frequent extraction with improved oral health care.

\section{Conclusion}

A number of methodologies both in vitro and in situ have been validated for measuring tooth wear from erosion. Many of these methods are sensitive and accurate, yielding valuable data. In vitro experiments provide data on the erosive potential which correlate with in situ results, and thus are valuable for preliminary work before embarking on more expensive clinical studies.

In situ models are particularly suited to assess erosion by beverages and the potential of various agents to provide protection against various erosive challenges. They enable the entire process of erosion to be monitored over time in a more or less completely natural environment of saliva, pellicle development and routine oral care. These methodologies can be employed alongside in vitro methods to help to develop and evaluate erosion-preventive methods.

\section{Disclosure Statement}

There are no potential conflicts of interest for any author.

\section{References}

-Abdullah AZ, Strafford SM, Brookes SJ, Duggal MS: The effect of copper on demineralization of dental enamel. J Dent Res 2006;85: 1011-1015.

Addy M: Tooth brushing, tooth wear and dentine hypersensitivity - are they associated? Int Dent J 2005;55:261-267.

-Al-Dlaigan YH, Shaw L, Smith A: Dental erosion in a group of British 14-year-old school children. Part II. Influence of dietary intake. $\mathrm{Br}$ Dent J 2001;190:258-261.

Amaechi B, Higham SM, Edgar WM: Development of an in situ model to study dental erosion; in Addy M, Embery G, Edgar WM, Orchardson R (eds): Tooth Wear and Sensitivity. London, Dunitz, 2000, pp 141-152.

Amaechi BT, Higham SM: In vitro remineralisation of eroded enamel lesions by saliva. J Dent 2001a;29:371-376.

-Amaechi BT, Higham SM: Eroded enamel lesion remineralization by saliva as a possible factor in the site-specificity of human dental erosion. Arch Oral Biol 2001b;46:697-703.
Amaechi BT, Higham SM, Edgar WM: The use of gamma irradiation for the sterilization of enamel for intra-oral cariogenicity tests. J Oral Rehabil 1999a;26:809-813.

Amaechi BT, Higham SM, Edgar WM: Factors influencing the development of dental erosion in vitro: enamel type, temperature and exposure time. J Oral Rehabil 1999b;26:624630.

Amaechi BT, Higham SM, Edgar WM, Milosevic A: Thickness of acquired salivary pellicle as a determinant of the sites of dental erosion. J Dent Res 1999c;78:1821-1828.

Amaechi BT, Ramalingam K, Mensinksai PK, Narjibfard K, Mackey AC, Karlinsey RL: Remineralization of eroded enamel by a NaF rinse containing a novel calcium phosphate agent in an in situ model: a pilot study. Clin Cosm Invest Dent 2010;2:93-100.

Arends J, Jongebloed WL: Crystallites dimensions of enamel. J Biol Buccale 1978;6:161171.
Attin T: Methods for assessment of dental erosion; in Lussi A (ed): Dental Erosion. From Diagnosis to Therapy. Monogr Oral Sci. Basel, Karger, 2006, vol 20, pp 152-172.

Attin T, Meyer K, Hellwig E, Buchalla W, Lennon AM: Effect of mineral supplements to citric acid on enamel erosion. Arch Oral Biol 2003;48:753-759.

- Barbour ME, Finke M, Parker DM, Hughes JA, Allen GC, Addy M: The relationship between enamel softening and erosion caused by soft drinks at a range of temperatures. J Dent 2006;34:207-213.

Barbour ME, Parker DM, Allen GC, Jandt KD: Human enamel erosion in constant composition citric acid solutions as a function of degree of saturation with respect to hydroxyapatite. J Oral Rehabil 2005a;32:16-21.

- Barbour ME, Shellis RP, Parker DM, Allen GC, Addy M: Investigation of some foodapproved polymers as agents to inhibit hydroxyapatite dissolution. Eur J Oral Sci 2005b;113:457-461. 
Bartlett D: Etiology and prevention of acid erosion. Compend Contin Educ Dent 2009;30: 616-620.

British Soft Drinks Association: The 2010 UK Soft Drinks Report. http://www. britishsoftdrinksassociation.com (accessed May 25, 2010).

Claytor FW, Smith WL, Turner EL: The effect of orange juice on gastric acidity. J Natl Med Assoc 1941;33:160-165.

Devlin H, Bassiouny MA, Boston D: Hardness of enamel exposed to Coca-Cola and artificial saliva. J Oral Rehabil 2006;33:26-30.

DeWald J: The use of extracted teeth for in vitro bonding studies: a review of infection control considerations. Dent Mater 1997;13:7481.

Featherstone JD, Mellberg JR: Relative rates of progress of artificial carious lesions in bovine, ovine and human enamel. Caries Res 1981;15:109-114.

- Ganss C, Neutard L, von Hinckeldey J, Klimek J, Schlueter N: Efficacy of a tin/fluoride rinse: a randomized in situ trial on erosion. J Dent Res 2010;89:1214-1218.

-Ganss C, Schlueter N, Friedrich D, Klimek J: Efficacy of waiting periods and topical fluoride treatment on toothbrush abrasion of eroded enamel in situ. Caries Res 2007;41:146-151.

-Gedalia I, Dakuar A, Shapira L, Lewinstein I, Goultschin J, Rahamin E: Enamel softening with Coca-Cola and rehardening with milk or saliva. Am J Dent 1991;4:120-122.

- Gregg T, Mace S, West NX, Addy M: A study in vitro of the abrasive effect of the tongue on enamel and dentine softened by acid erosion. Caries Res 2004;38:557-560.

-Hannig C, Spitzmüller B, Lux HC, Altenburger M, Al-Ahmad A, Hannig M: Efficacy of enzymatic toothpastes for immobilisation of protective enzymes in the in situ pellicle. Arch Oral Biol 2010;55:463-469.

-Hannig M, Fiebiger M, Güntzer M, Döbert A, Zimehl R, Nekrashevych Y: Protective effect of the in situ formed short-term salivary pellicle. Arch Oral Biol 2004;49:903-910.

- Hara AT, Ando M, González-Cabezas C, Cury JA, Serra MC, Zero DT: Protective effect of the dental pellicle against erosive challenges in situ. J Dent Res 2006;85:612-616.

- Hara AT, Kelly SA, González-Cabezas C, Eckert GJ, Barlow AP, Mason SC, Zero DT: Influence of fluoride availability of dentifrices on eroded enamel remineralization in situ. Caries Res 2009;43:57-63.

Honório HM, Rios D, Santos CF, Magalhães AC, Buzalaf MA, Machado MA: Effects of erosive, cariogenic or combined erosive/cariogenic challenges on human enamel: an in situ/ex vivo study. Caries Res 2008;42:454459.

Hooper S, Hughes J, Parker D, Finke M, Newcombe RG, Addy M, West NX: A clinical study in situ to assess the effect of a food approved polymer on the erosion potential of drinks. J Dent 2007b;35:541-546.
Hooper SM, Newcombe RG, Faller R, Eversole S, Addy M, West NX: The protective effects of toothpaste against erosion by orange juice: studies in situ and in vitro. J Dent 2007a;35: 476-481.

Hove LH, Young A, Tveit AB: An in vitro study on the effect of $\mathrm{TiF}_{4}$ treatment against erosion by hydrochloric acid on pellicle-covered enamel. Caries Res 2007;41:80-84.

-Hughes J, West NX, Parker D, Newcomb RG, Addy M: Development and evaluation of a low erosive blackcurrant drink in vitro and in situ. 1. Comparison with orange juice. J Dent 1999a;27:285-289.

Hughes J, West NX, Parker D, Newcombe RG, Addy M: Development and evaluation of a low erosive blackcurrant juice drink. 3. Final drink and concentrate, formulae comparisons in situ and overview of the concept. J Dent 1999b;27:345-350.

- Hughes JA, West NX, Parker DM, van den Braak $\mathrm{MH}$, Addy M: Effects of $\mathrm{pH}$ and concentration of citric, malic and lactic acids on enamel in vitro. J Dent 2000;28:147-152.

Human Tissue Authority: Code of practice 9. Research (September 2009). http://www. hta.gov.uk/legislationpoliciesandcodesof practice/codesofpractice/code9research. cfm (accessed 2010).

Huysmans MCDNJM, Chew HP, Ellwood RP: Clinical studies of dental erosion and erosive wear. Caries Res 2011;45(suppl 1):60-68.

ICH Harmonised Tripartite Guideline. Guideline for Good Clinical Practice: E6(R1). Institute of Clinical Research, 1996 (http:// www.ich.org/fileadmin/Public_Web_Site/ ICH_Products/Guidelines/Efficacy/E6_R1/ Step4/E6_R1__Guideline.pdf).

Kato MT, Leite AL, Hannas AR, Buzalaf MA: Gels containing MMP inhibitors prevent dental erosion in situ. J Dent Res 2010;89: 468-472.

Kielbassa AM, Hellwig E, Meyer-Lückel H: The effects of irradiation on in vitro demineralization and in situ remineralization of human and bovine enamel. Caries Res 2006;40: 130-135.

Laheij AM, van Strijp AJ, van Loveren C: In situ remineralisation of enamel and dentin after the use of an amine fluoride mouthrinse in addition to twice daily brushings with amine fluoride toothpaste. Caries Res 2010;44:260266.

Lee VA, Karthikeyan R, Rawls HR, Amaechi BT: Anti-cariogenic effect of a cetylpyridinium chloride-containing nanoemulsion. J Dent 2010;38:742-749.

Leung VW, Darvell BW: Artificial salivas for in vitro studies of dental materials. J Dent 1997; 25:475-484.

Lopes MB, Sinhoreti MA, Gonini Júnior A, Consani S, McCabe JF: Comparative study of tubular diameter and quantity for human and bovine dentin at different depths. Braz Dent J 2009;20:279-283.
Magalhães AC, Levy FM, Rios D, Buzalaf MA: Effect of a single application of $\mathrm{TiF}_{4}$ and $\mathrm{NaF}$ varnishes and solutions on dentin erosion in vitro. J Dent 2010;38:153-157.

Magalhães AC, Wiegand A, Rios D, Hannas A, Attin T, Buzalaf MA: Chlorhexidine and green tea extract reduce dentin erosion and abrasion in situ. J Dent 2009;37:994-998.

-Mandel ID: The functions of saliva. J Dent Res 1987;66:623-627.

Mannerberg F: Saliva factors in cases of erosion. Odont Revy 1963;14:156-166.

- Meurman JH, Rytömaa I, Kari K, Laakso T, Murtömaa H: Salivary $\mathrm{pH}$ and sugar after consuming beverages and other soft drinks. Caries Res 1987;21:353-359.

Meurman JH, ten Cate JM: Pathogenesis and modifying factors of dental erosion. Eur J Oral Sci 1996;104:199-206.

-Miekka SI, Forng RY, Rohwer RG, MacAuley C, Stafford RE, Flack SL, MacPhee M, Kent RS, Drohan WN: Inactivation of viral and prion pathogens by gamma-irradiation under conditions that maintain the integrity of human albumin. Vox Sang 2003;84:36-44.

Research and Markets: Soft Drinks in the BRIC (Brazil, Russia, India, China) Countries - Market Overview and Forecasts to 2013. Datamonitor, July 2010 (http://www. researchandmarkets.com/reports/1280799).

Rios D, Honório HM, Magalhães AC, Delbem AC, Machado MA, Silva SM, Buzalaf MA: Effect of salivary stimulation on erosion of human and bovine enamel subjected or not to subsequent abrasion: an in situ/ex vivo study. Caries Res 2006;40:218-223.

Rios D, Honório HM, Magalhães AC, Wiegand A, de Andrade Moreira Machado MA, Buzalaf MA: Light cola drink is less erosive than the regular one: an in situ/ex vivo study. J Dent 2009;37:163-166.

-Rios D, Magalhães AC, Polo RO, Wiegand A, Attin T, Buzalaf MA: The efficacy of a highly concentrated fluoride dentifrice on bovine enamel subjected to erosion and abrasion. J Am Dent Assoc 2008;139:1652-1656.

Schipper RG, Silletti E, Vingerhoeds MH: Saliva as research material: biochemical, physicochemical and practical aspects. Arch Oral Biol 2007;52:1114-1135.

-Schlueter N, Hara A, Shellis RP, Ganss C: Methods for measurement and characterization of erosion in enamel and dentine. Caries Res 2011;45(suppl 1):13-23.

- Tahmassebi JF, Duggal MS, Malik-Kotru G, Curzon ME: Soft drinks and dental health: a review of the current literature. J Dent 2006; 34:2-11.

- Tanaka JL, Medici Filho E, Salgado JA, Salgado MA, Moraes LC, Moraes ME, Castilho LC: Comparative analysis of human and bovine teeth: radiographic density. Braz Oral Res 2008;22:346-351.

- Tucker K, Adams M, Shaw L, Smith AJ: Human enamel as a substrate for in vitro acid dissolution studies and influence of tooth surface and morphology. Caries Res 1998;32:135-140. 
Vieira A, Jager DH, Ruben JL, Huysmans MC: Inhibition of erosive wear by fluoride varnish. Caries Res 2007;41:61-67.

-Vieira A, Overweg E, Ruben JL, Huysmans MC: Toothbrush abrasion, simulated tongue friction and attrition of eroded bovine enamel in vitro. J Dent 2006;34:336-342.

-Wegehaupt F, Gries D, Wiegand A, Attin T: Is bovine dentine an appropriate substitute for human dentine in erosion/abrasion tests? J Oral Rehabil 2008;35:390-394.

-West NX, Hughes J, Addy M, Parker D, DarbyDowman A: Development of low erosive carbonated fruit drinks. 2. Evaluation of an experimental carbonated blackcurrant drink compared to a conventional carbonated drink. J Dent 2003;31:361-365.

-West NX, Hughes J, Parker D, Newcombe RG, Addy M: Development and evaluation of a low erosive blackcurrant juice drink. 2. Comparison with a conventional blackcurrant drink and orange juice. J Dent 1999; 27:341-344.
World Health Organisation: WHO Infection Control Guidelines for Transmissible Spongiform Encephalopathies: Report of a WHO Consultation. Geneva, WHO, 1999 (http://whqlibdoc.who.int/hq/2000/WHO_ CDS_CSR_APH_2000.3.pdf, 1999). 2000;27:875-880.

West NX, Hughes JA, Parker D, Weaver LJ, Moohan M, De'Ath J, Addy M: Modification of soft drinks with xanthan gum to minimise erosion. Br Dent J 2004;196:478-481.

West NX, Maxwell A, Addy M, Parker D, Jackson RJ: A method to measure clinical erosion: the effect of orange juice consumption on erosion of enamel. J Dent 1998;4:329-335.

Wetton S, Hughes J, West NX, Addy M: Exposure time of enamel and dentine to saliva for protection against erosion. A study in vitro. Caries Res 2006;40:213-217.
Wiegand A, Bichsel D, Magalhães AC, Becker K, Attin T: Effect of sodium, amine and stannous fluoride at the same concentration and different $\mathrm{pH}$ on in vitro erosion. J Dent 2009; 37:591-595.

Young A, Tenuta LM: Initial erosion models. Caries Res 2011;45(suppl 1):33-42.

Young A, Thrane PS, Saxegaard E, Jonski G, Rölla G: Effect of stannous fluoride toothpaste on erosion-like lesions: an in vivo study. Eur J Oral Sci 2006;114:180-183.

Zero DT, Hara AT, Kelly SA, González-Cabezas C, Eckert GJ, Barlow AP, Mason SC: Evaluation of a desensitizing test dentifrice using an in situ erosion remineralization model. J Clin Dent 2006;17:112-116. 